\title{
Influence of User Behavior on Energy Consumption and Its Relation With Comfort. A Case Study Based on Sensor and Crowd-Sensed Data
}

Robert Rusek ( $\square$ robert.rusek@udg.edu )

University of Girona: Universitat de Girona https://orcid.org/0000-0003-3801-2499

Joaquim Melendez Frigola

University of Girona: Universitat de Girona

Joan Colomer Llinas

University of Girona: Universitat de Girona

Original article

Keywords: Crowd-sensing, energy behavior, energy efficiency, indoor comfort, occupancy patterns

Posted Date: February 8th, 2021

DOl: https://doi.org/10.21203/rs.3.rs-163089/v1

License: (c) (1) This work is licensed under a Creative Commons Attribution 4.0 International License.

Read Full License 


\section{Abstract}

\section{Background}

In recent years monitoring of user behavior became an imperative for building energy optimization. Very often there is a significant discrepancy between predicted building energy performance at the design stage and the actual one rendered during the building operation. This stems from the difference in users' behavior. In spite of that, users' interaction and feedback is rarely taken into account and evidence of the impact of occupants' behavior on energy consumption is still scarce. Thus, the purpose of this study is to apply crowd-sensing techniques to understand how energy is consumed, define appropriate performance indicators, and provide inputs for building operations on more efficient use of resources.

\section{Methods}

Monitoring strategies were implemented in an office lab with controlled variables to collect quality data on occupancy patterns, ambient factors and energy consumption. In addition, crowd-sensing techniques were applied to model user behavior at different ambient conditions over time and to contrast this behavior with energy consumption patterns combined with new inquiry tools to identify how occupants perceive their comfort level. Also, a set of energy efficiency indicators was used to compare energy performance in different periods.

\section{Results}

It was found out, that there is a strong relation between users' behavior and energy consumption, however, more than $50 \%$ of energy was consumed when no users' activity was registered. Energy performance indicators revealed that measuring energy efficiency in terms of kWh per surface area encourages less efficient use of space and therefore including coefficient of person hours is advised. It was also found out that users do not relay fully on feedback mechanism and they rather prefer to take an action to adapt the ambient conditions instead of simply expressing their opinion. Analysis of energy usage during the covid-19 lock down revealed substantial use of energy unlike it was expected. It was because home computers were used only as terminals, while the actual tasks were performed on the lab computers with remote desktop connection turned on 24/7. In addition, energy consumed by each employee at their home has to be taken into account. Moreover, a set of practical recommendations was formulated.

\section{Background}

In recent years monitoring of user behavior became an imperative for building energy optimization, as it was realized that buildings do not consume energy by themselves but it is their occupants who render the energy demand and expect it to be satisfied. It is well known, that very often there is a significant discrepancy between predicted building energy performance at the design stage and the actual one rendered during the building operation. This discrepancy stems from the difference in users' behavior, 
which is difficult to predict a priori, but significantly influences the energy demand causing that predicted and actual energy performance differs (Martincigh at al., 2016; Karatas et al., 2016; Yan et al., 2015). In the design phase, the operational energy consumption is typically simulated using standard occupancy schedules (D'Oca, Hong, 2015). Such predictions may differ by $46 \%$ from the real energy demand (Duarte et al.2013). What is more, lack of proper adaptation of building management based on users' behavior, may lead to $30 \%-50 \%$ waste due to the misuse and non-optimal management (Laslaet al., 2019). In addition, there is a mismatch between initially designed and real building uses (activities, occupancy, etc.) that evolve continuously. Buildings experience changes over time, they are refurbished or repurposed serving in different ways or hosting completely different activities than those they were designed for. These circumstances have direct implications on building performance and demand new strategies for better user behavior and energy demand sensing in order to perform in an optimal way.

\subsection{Influence of user behavior on energy consumption}

The importance of user behavior and occupation patterns for energy efficiency was stressed in numerous studies for over a decade, e.g.: Yezioro and Dong, 2008; Virote and Neves-Silva., 2012; Li et al., 2015; Sandels, et al., 2015; Wang and Ding., 2015; Song et al., 2017; Zhao at al., 2017, Paone and Bacher, 2018. In spite of that, users' interaction and their feedback is rarely taken into account and evidence of the impact of occupants' behavior on energy consumption is scarce (Zhao at al., 2017). At the same time Ericson et al., 2014 demonstrated potential for $42 \%$ energy savings using real time occupancy data based on sensor network, and Taylor (2015) shown over 10\% energy cost savings in a large scale sample of 280 buildings. However, building occupancy is rarely monitored in a reliable way, and the estimations often rely only on facility managers' observations or surveys that might present inaccurate results (Huovila, et al., 2017).

Covid-19 pandemic showed very clearly the impact of user behavior on energy consumption. There used to be a strong emphasis on promoting interactions between coworkers reflected in the building design (Hayness, 2007). The pandemic, however, has changed human behavior and limited interactions drastically. Social distancing and teleworking made a substantial impact on working conditions and altered significantly the energy consumption patterns.

\subsection{Energy consumption and user comfort balance}

In addition to energy efficiency, yet another challenge is how to achieve balance between optimal use of energy and comfortable conditions for the users. Since people spend a large part of their lives indoor, comfort or discomfort sensation may have a great impact not only on their productivity but also on their health and general well-being (Horr et al., 2016). This is why user comfort should always be taken into account as an integral part of energy management strategies (Martell et al., 2020). For this reason, various indoor comfort standards were developed, such as The American Standard ASHRAEE 55 (2017), or European ISO Standard 7730 (2005), both aimed at defining the optimal indoor comfort level of working conditions. Despite the validity of these standards, gaps between the defined comfort conditions and those experienced by the occupants have been perceived. People coming from different geographical 
locations used to show comfort expectations depending on their provenance (Martincigh et al., 2016). Other factors, such as differences between genders may also play role (Haynes et al., 2017). Moreover, controls of heating, air conditioning, window opening or even light are often inaccessible for the users due to lack of will or safety reasons, leaving individual preferences and comfort needs unaddressed. This is why users' opinions should be considered as complementary to the comfort standards in order to efficiently manage energy usage on the one side and assure comfortable indoor conditions, on the other.

\subsection{Acquisition of energy-related user behavior data}

Building occupants used to be underutilized as a source of information, while the key to ensure a balance between energy efficiency and comfort lies in data on user behavior in conjunction with their feedback and opinion. Crowd-sensing technology is ideally suited for this purpose. Crowd-sensing is an emerging paradigm that empowers users to provide data sensed or generated from their mobile devices (phones, wearables, etc.). It exploits the concept of human sensor to provide an insight on user behavior, improving observability of spaces and the way users interact with the indoor environment (Zhu et al. 2015). Since energy consumption in buildings depends in great part on users' behavior (Erickson, Carreira-Perpiñán and Cerpa, 2014), crowd-sensing may support energy management by providing highly valuable information on occupancy, users' behavior and their interaction, but also give the users a possibility to express their needs.

Therefore, the purpose of this study is to take advantage of the crowd-sensing techniques to identify the occupancy patterns and find out to what extent these patterns are correlated with energy consumption and what impact it has on users' comfort. Does the higher occupation translate into higher energy consumption? And moreover, to understand how energy is consumed, define appropriate performance indicators, and provide inputs for building operations on more efficient use of resources.

\section{Methods}

Understanding of the way in which energy is consumed, requires awareness on the users' behavior and space occupancy. A variety of methods in behavioural studies which rely on human researchers such as surveys, focus groups or human observation, have been used for this purpose (Aragon et al., 2019). However, still collecting accurate, longitudinal data on user behaviour remains a challenge.

\subsection{Case study}

Monitoring strategies were implemented in an office lab with controlled variables to facilitate the validation and collection of quality data. This aimed to model the user behavior at different environmental indoor conditions over time and to contrast this behavior with energy consumption patterns combined with new inquiry tools to identify how occupants perceive their comfort level. The experiment took place in a research facility building located in Girona, Spain, with Mediterranean climate with maximum average temperatures in February of $18.3^{\circ} \mathrm{C}$ and in July of $33^{\circ} \mathrm{C}$ (meteo.cat, 2020). The office lab of $72 \mathrm{~m}^{2}$ and illuminated with fluorescent lamps was chosen to carry out the study. The lab 
consists of 16 workstations with desktop computers and has been equipped with sensors measuring indoor environmental conditions (figure 1). In addition, each workstation was equipped with sensors measuring energy consumption.

According to Pérez-Lombard et al. (2008), heating and air conditioning accounts for $50 \%$ of the energy consumed in office buildings, while the other $50 \%$ is rendered by user-related activities such as lighting and appliances. This study specifically focuses on energy consumption rendered by user-related activities. For this reason, energy consumption of workstations and light was considered since these two elements are directly influenced by users' activity. Central heating and air conditioning systems were not included in this study since they are centrally managed and their energy consumption does not depend on the number of users. Furthermore, relation between temperature and energy consumption rendered by heating and air conditioning systems is obvious and was a subject of many previous studies (Santin, 2011; Zhao and Magoulès, 2012; Yang, Yan and Lam, 2014).

\subsection{Time span}

Building energy behavior tends to show some typical annual, weekly and daily patterns (Mikulik, 2018), thus in order to measure and compare possible differences in user behavior and energy consumption patterns in different time periods, the experiment was divided into two phases. The first one covered a four-week period in July 2019 and a four-week period in February 2020. Later, the results of the experiment were compared with two other four-week periods: spring and autumn 2020.

\subsection{Users}

There were 16 users (employees, occupants: 2 females and 14 males) in the summer period and 14 users ( 2 females and 12 males) in the winter period, as well as 4 users in the autumn period. Due to the lock down caused by covid-19 pandemic, users' participation in the spring period was not possible. The employees performed their usual, daily tasks without being advised that their energy behavior is monitored in order not to alter the results. However, they were asked to provide feedback on their satisfaction with comfort level and also had the possibility of adjusting some of the factors influencing their comfort (light, access to thermostat, possibility to open windows). An automatic reminder was set

up to notify the users about giving their opinion. One of the authors of this article was also present in the case area during the whole duration of the experiment.

\subsection{Objective vs subjective measurements}

To uncover users' behavior patterns and their possible relations with energy consumption and environmental factors, two types of datasets were required: objective (sensor-based), as well as subjective (user-based).

Objective aspects were strictly related with the energy behavior (time and amount of energy used per workstation), indoor environment measurements (temperature, humidity, pressure, noise level, light, door/window opening) as well as occupancy (time and space). Many studies attempt to increase energy 
efficiency using occupancy schedules for simplicity and due to lack of readily available data (Song et al., 2017). In this study real occupancy data from sensors combined with crowd-sensed data from users' mobile devices was used. This data was complemented with outdoor environment data coming from the weather station installed outside of the lab and has been stored with frequency of ten minutes.

Subjective aspects were associated with the occupants' perceived comfort levels. For the collection of the subjective data, crowd-sensing techniques have been applied. To uncover the occupation patterns and find out users' opinion on comfort levels, a mobile app has been developed and the occupants were asked to voluntarily install it on their devices. The app recognized users' location based on the Wi-Fi signal and gave a possibility for expressing the level of comfort in four aspects according to the scale for comfort and temperature sensation proposed by Gagge et al., (1967): general comfort (comfortable, slightly uncomfortable, uncomfortable, very uncomfortable), thermal comfort (cold, slightly cool, slightly warm, hot), visual comfort (very dark, slightly dark, slightly bright, very bright) and acoustic comfort (silently, slightly noisy, noisy, very noisy). The app presented this scale in an intuitive and user friendly manner as shown in figure 2 .

It must be stressed that use of personal devices for data collection on users' behavior may raise concerns of privacy violation and security risks. Therefore, for the purpose of this study, the participants were assured that data will be aggregated in order not to reveal personal details.

\subsection{Data preparation and preprocessing}

Assuring good quality of data is essential for data analytics in order to obtain reliable results and in consequence, draw accurate conclusions. Therefore, previous data preparation was necessary. For the purpose of this experiment, the following datasets, encompassing four week periods each, have been obtained:

- July 2019 (summer) - objective, sensor-based data and subjective crowd-sensed data;

- February 2020 (winter) - objective, sensor-based data and subjective crowd-sensed data;

- April 2020 (spring) - objective, sensor-based data;

- November 2020 (autumn) - objective, sensor-based data.

First, objective and subjective datasets were merged. The objective data was saved with ten-minute frequency; however subjective data was saved asynchronously at the time of users' feedback. For this reason, the timestamp of the subjective datasets was rounded to the nearest 10 minute and both datasets were merged. Then, to deal with missing values in sensor-based datasets, an interpolation for cyclic weekly data was created - a linear interpolation between last known week, day, hour, minute with the next known same week, day, hour, minute. For initial or final missing values, the last available day values were used, and in case of variables such as temperature, the closest known value was used.

The light consumption data, which represented some error values due to the temporal malfunction of the sensor, was recreated based on occupation pattern. Due to a low amount of natural light in the lab, 
artificial illumination is always used whenever users are present (regardless the number of occupants), therefore the curve of energy consumption rendered by light follows the occupation pattern. Taking this into account and the fact that energy consumption of light is almost binary - 0 when it is off and approximately 23 Wh (Light 1 ) and 56 Wh (Light 2) when it is on, the corrupted data was recreated according to the occupancy pattern.

Having done such data pre-processing allows for further analysis, obtaining reliable results and in consequence, drawing well founded conclusions.

\section{Results}

\subsection{Users' behavior and energy consumption patterns}

Energy consumption pattern and its relation with users' behavior, comfort and environmental factors was investigated to uncover energy saving potential. Unlike residential buildings, where behavior of inhabitants is not conditioned by strict time schedules, occupation of office buildings usually is a result of well-defined timetables. However, number of occupants variates along the day. Thus, occupation pattern and its relation with energy consumption has been examined on the example of the office lab. As figure 3 demonstrates, the number of users increases from around 9:00 am and reaches its peak just before the midday. Then, around 1:00 - 2:00 pm it decreases, as a result of a lunchtime brake, and it rises slightly again in the early afternoon, to go down completely around 6:00 pm when users leave for home. This pattern is very similar for all weekdays. In addition, on Monday and Wednesday some minor activity can be observed before 9:00 am caused by the cleaning service who maintains the lab twice a week.

A strong correlation between users' behavior and energy consumption can be noticed since both curves are relatively parallel. Nevertheless, a significant use of energy is observed even in periods with no users' activity: evenings, nights and weekends. This is due to the consumption rendered by three servers and some workstations executing computation tasks which are turned on constantly. The total energy consumption rendered by users of the office lab, during two four-week periods: summer 2019 and winter 2020, has been summarized in table 1 .

Table 1 Comparison of energy consumption in summer and winter periods.

\begin{tabular}{|lllll|}
\hline & \multicolumn{3}{l}{ Summer 2019} & \multicolumn{2}{l|}{ Winter 2020} \\
& $\mathrm{kWh}$ & $\%$ & $\mathrm{kWh}$ & $\%$ \\
\hline Total energy consumption & 543.2 & 100 & 555.2 & 100 \\
\hline Energy consumption working hours[1] & 259.0 & 48 & 216.8 & 39 \\
\hline Energy consumption afterhours[2] & 284.2 & 52 & 338.3 & 61 \\
\hline
\end{tabular}


This clearly demonstrates that in spite of unquestionable correlation between energy use and occupation, the majority of energy consumption ( $52 \%$ in the summer period and $61 \%$ in the winter period) was rendered after hours when no users' activity was registered.

To get a better picture and identify the sources of major consumption, energy demand of workstations was compared for the summer and winter periods in figure 4.

As figure 4 shows, workstations $1,5,11,12,13,15$ and 16 turned out to be the most energy intensive with consumption exceeding the mean value. The distribution of appliances in the lab shown in figure 1 helps to understand this result. Workstation 1 in the summer period was shared with a server, which was removed latter. This explains significantly lower energy consumption in the winter. On workstation 5 , a very powerful machine was used to process complex tasks which resulted in higher consumption than those of the other workstations. Occasionally some other devices were plugged in too, which impacted the total consumption. The same applies to the workstation 12 in the winter period. Workstation 11 was turned on almost all the time in the summer period and turned off for the weekends in the winter, which explains the difference in consumption between these two periods. Number 13 encompasses two workstations located in close proximity. And workstations 15 and 16 were shared with servers.

\subsection{Energy efficiency indicators}

In order to obtain a deeper insight and measure the energy efficiency, a set of indicators was used. The most common one correlates energy consumption with space area $\left(\mathrm{kWh} / \mathrm{m}^{2}\right)$. This indicator refers to technical properties of the building and as it was argued by Huovila et al. (2017) it may be useful at the design and planning stage; however, it omits the actual user activity which is crucial in building operation phase. Users' activity has a tremendous impact on building energy performance which may lead to a considerable discrepancy between the predicted and actual energy consumption of buildings (Yang, Santamouris and Lee, 2016; Calì et al., 2016). For this reason, understanding of the human activity and the interplay of building occupancy and energy consumption is essential. This is why $\mathrm{kWh} / \mathrm{m}^{2}$ indicator was complemented with others, that consider human factor: 1) $\mathrm{kWh}$ /person which correlates use of energy with the number of occupants; 2 ) $\mathrm{kWh}$ /person hours, which correlates the energy consumption with the actual sum of the number of hours that users spend in the building, or its specific area, during the given period of time. For the sake of this study, periods of four weeks were examined; 3$) \mathrm{kWh} / \mathrm{m}^{2}$ person hours, which combines indicators 1 ) and 2), to take into account floor area as well as its occupation time according to the formula:

Energy per area per occupied hours $=$, where $k W h$ is the amount of energy consumed during the given period of time, $m^{2}$ is the floor area of the space in question, and $h$ is the number of hours the space was occupied during the given period (Dooley, 2011).

The performance of the office lab according to these four indicators was compared in table 2.

Table 2 comparison of energy indicators of the office lab in the summer and winter periods. 


\begin{tabular}{|llllllllll|}
\hline & $\mathrm{m}^{2}$ & $\begin{array}{l}\text { No. of } \\
\text { users }\end{array}$ & $\mathrm{kWh}$ & $\begin{array}{l}\mathrm{m}^{2} / \\
\text { person }\end{array}$ & $\begin{array}{l}\mathrm{kWh} / \\
\mathrm{m}^{2}\end{array}$ & $\begin{array}{l}\mathrm{kWh} / \\
\text { workstation }\end{array}$ & $\begin{array}{l}\mathrm{kWh} / \\
\text { person }\end{array}$ & $\begin{array}{l}\mathrm{kWh} / \\
\text { person } \\
\text { hours }\end{array}$ & $\begin{array}{l}\mathrm{kWh} / \\
\mathrm{m}^{2} \text {, } \\
\text { person } \\
\text { hours }\end{array}$ \\
\hline Summer & 72 & 16 & 543.2 & 4.5 & 7.5 & 28.2 & 34.0 & 3.1 & 43 \\
\hline Winter & 14 & 555.2 & 5.1 & 7.7 & 29.3 & 39.7 & 3.9 & 54 \\
\hline
\end{tabular}

Perversely, in spite of a greater number of users, less energy was consumed in the summer period. Spanish norm for occupation defines the standard of minimum $5 \mathrm{~m}^{2}$ per person for this kind of space (Ministerio de Fomento, 2019), for which in the summer period the office lab was slightly overused with only $4.5 \mathrm{~m}^{2} /$ person. This translated into higher energy efficiency shown by other indicators. It is worth to stress that the difference in these two periods is especially seen in the case of indicators that involve human factor.

\subsection{Covid-19 lock down and post lock down impact on office energy efficiency}

Year 2020 was unprecedented and differed from the previous years in many aspects among which energy use and energy related human behavior are no exception. Specifically, in Spain, during the spring and summer of 2020 all the work was carried out from home due to the lock down. Then, in the autumn, the employees came back to their offices but only partially with limited hours and partially working from their homes. Table 3 shows energy consumption of the office lab in these two periods.

Table 3 Comparison of energy consumption in spring and autumn periods.

\begin{tabular}{|lllll|}
\hline & \multicolumn{3}{l}{ Spring 2020} & \multicolumn{2}{l|}{ Autumn 2020} \\
\hline & $\mathrm{kWh}$ & $\%$ & $\mathrm{kWh}$ & $\%$ \\
\hline Total energy consumption & 420.4 & 100 & 322.7 & 100 \\
\hline Energy consumption working hours[3] & - & - & 72 & 22 \\
\hline Energy consumption afterhours[4] & - & - & 251 & 78 \\
\hline
\end{tabular}

It can be seen that in spite of the lack of physical presence of employees in the spring period, the energy consumption is significantly higher than in the autumn when employees partially returned to the office. At first glance, this could be interpreted as an inverse relationship between occupation and energy consumption. However, it is because some employees used home computers only as terminals, while the actual tasks were performed on the lab computers with remote desktop connection. These computers were not turned off every day after work (as it normally happens), but were turned on 24/7 instead, which explains higher energy consumption. Since during the autumn period, work was carried on in a semi remote mode, the energy consumption was lower. However, still great part of energy (78\%) was consumed afterhours. Nevertheless, it is important to stress for both, spring as well as autumn periods that 
significantly lower energy consumption in comparison with the summer and winter periods was caused by the fact, that energy consumed by the employees at their homes was not taken into account, although it should be included. However, collecting such data in practice is impossible and may be only estimated.

In order to have a deeper insight and show how drastic change of users' behavior (homeworking) caused by covid-19 outbreak impacted the energy efficiency, a set of indicators has been calculated for the spring and autumn periods and presented in table 4.

Table 4 comparison of energy indicators of the office lab in the spring and autumn periods.

\begin{tabular}{|llllllllll|}
\hline & $\mathrm{m}^{2}$ & $\begin{array}{l}\text { No. of } \\
\text { users }\end{array}$ & $\mathrm{kWh}$ & $\begin{array}{l}\mathrm{m}^{2} / \\
\text { person }\end{array}$ & $\begin{array}{l}\mathrm{kWh} / \\
\mathrm{m}^{2}\end{array}$ & $\begin{array}{l}\mathrm{kWh} / \\
\text { workstation }\end{array}$ & $\begin{array}{l}\mathrm{kWh} / \\
\text { person }\end{array}$ & $\begin{array}{l}\mathrm{kWh} / \\
\text { person } \\
\text { hours }\end{array}$ & $\begin{array}{l}\mathrm{kWh} / \mathrm{m}^{2}, \\
\text { person } \\
\text { hours }\end{array}$ \\
\hline Spring & 72 & 0 & 420.4 & - & 5.8 & 26.3 & - & - & - \\
\hline Autumn & 4 & 322.7 & 18 & 4.5 & 20 & 80.7 & 4.0 & 56 \\
\hline
\end{tabular}

Comparison of values from table 2 and table 4 shows how consideration of users' behavior is important for more realistic picture of the situation. The number of $\mathrm{kWh} / \mathrm{m}^{2}$ for spring and autumn is clearly lower than in the summer and winter periods which may suggest higher efficiency. However, looking at the indicators that include human activity, a more realistic overview can be obtained. $\mathrm{kWh} /$ person, $\mathrm{kWh} /$ person hours, as well as $\mathrm{kWh} / \mathrm{m}^{2} /$ person hours are higher in the autumn then summer and winter periods (obtaining these indicators for the spring period was not possible due to the lock down). This is because the more effectively a space is used, the more it consumes in absolute numbers. And the higher the occupancy and space efficiency, the less the building or space tends to appear when the indicator of energy consumption per floor area is used $\left(\mathrm{kWh} / \mathrm{m}^{2}\right)$ since more users render a higher energy demand, while the floor area remains constant (Dooley, 2011; Martani et al., 2012).

\subsection{Comfort}

User feedback on comfort was investigated to find out possible relation between energy consumption and comfort levels. Comfort can be defined as a condition of mind which expresses satisfaction with the environment (ASHRAE, 1997). Energy consumption may have a direct impact on such a steady state sensation. For this reason, during the summer and winter periods, users were asked to use a mobile crowd sensing app and provide feedback on their level of comfort. Figure 5 shows comparison of general, thermal, visual and acoustic comfort levels in the summer and winter.

The general comfort in the summer and in the winter was close to optimal with $69 \%$ and $80 \%$ opinions on comfortable and slightly uncomfortable. The result of thermal comfort in the summer period, however is not so clear with $38 \%$ of slightly cool and only $20 \%$ of hot. Especially surprising is $2 \%$ of cold in the summer voted when the indoor temperature during the working hours fluctuated between $26.7^{\circ} \mathrm{C}$ and $28.7^{\circ} \mathrm{C}$ while the European standard EN 15251 (2007) defines the summer comfort temperature in the 
range between $23^{\circ} \mathrm{C}$ and $26^{\circ} \mathrm{C}$. Figure 6 shows that there is no strict relation between temperature and users' thermal comfort sensation. Especially it can be seen that the same range of temperatures $\left(25^{\circ} \mathrm{C}\right.$ $26^{\circ} \mathrm{C}$ ) in the summer is considered as slightly cool or even cold, while it is considered slightly warm or even hot in the winter.

It can be also observed that lighting conditions were close to optimal (figure 7). The greatest number of votes ( $81 \%$ in the summer and $71 \%$ in the winter) described visual comfort as slightly bright. According to the European standard UNI EN 12464-1(2011), a comfortable minimum illumination level should be between 500 and $700 \mathrm{~lx}$ and indeed the light intensity in the lab was maintained on the level of $>500 \mathrm{~lx}$ almost all the time during the experiment. In practice, on many occasions it was much higher especially in the summer time. What is surprising, is that significantly lower light conditions in the winter period have almost no impact on users' satisfaction which is very comparable for the summer and winter period.

The noise level was rather satisfactory with far majority of votes for silence and low noise and with only few complaints about high noise (figure 8). The maximum registered values did not exceed the level of $80 \mathrm{db}$ which is a limit of comfort defined in the standard (EU Directive 2003/10/EC, 2003). Also no significant differences were observed between summer and winter periods. However, it must be stressed that the sensor sensibility was limited and noise levels lower that $50 \mathrm{db}$ were not registered.

In terms of gender, the results were almost the same for men and women. However, this result is not objective due to the significant disproportion between the number of representatives of both sexes - 16 males and 2 females in the summer period, and 14 males and 2 females in the winter period.

After all, it is not surprising that even in the optimal conditions that complies with the standard, there will always be some percentage of dissatisfied users. This is because human beings are individuals and there is no unique definition of comfort conditions. Such thesis was already stated fifty years ago saying that there is no ambient condition that can make all individuals feel equally comfortable (Fanger 1970).

\subsection{Level of thermal tolerance}

Users' comfort or discomfort sensation is conditioned by a mixture of different environmental factors, such as humidity or atmospheric pressure, which are rather not easy to identify unless they reach extreme values. Nonetheless hot or cold sensation is very easy to pinpoint even if the variation is only of a few degrees. Temperature is the most easily noticeable and most influential factor that determines the level of comfort (Djekic, et al., 2018). For this reason, a level of thermal tolerance of occupants in the office lab was studied. To this end, on $17^{\text {th }}$ of February 2020, without notifying the users, the heating temperature was slowly increased to find out the threshold between thermal comfort and discomfort (sensation of hot). It was expected that at certain point users would start to express their dissatisfaction by choosing the hot option in the crowd sensing app. As it can be seen in figure 9, this moment was reached at about 13:10, when the temperature exceeded the border of $26^{\circ} \mathrm{C}$. After that, the decrease of temperature can be observed until the level of about $24.6^{\circ} \mathrm{C}$, which in this case can be understood as a comfort level. This 
observation was checked and compared with users' opinion on comfort to reveal that surprisingly users did not complaint much regarding the temperature. Only one vote at 13:06 indicates hot sensation. The others are more moderate.

Comparing this result with the data form other sensors revealed the cause of the decrease of temperature. At 13:00 all the windows were opened and the heating was turned off. The windows were closed later at 13:50, while the heating remained off for the rest of the day. This demonstrates, that users, in spite of having a possibility to express their opinion on comfort, rather prefer to act instead. They probably cannot see the direct impact of their opinion on the enhancement of comfort. Thus, they prefer to take an action (turn off the heating, open windows) instead of expressing their opinion which does not translates their needs immediately.

\subsection{Correlation between energy consumption, comfort level and environmental factors}

In order to obtain a deeper insight on energy performance, possible correlations between energy consumption, users' comfort and environmental factors were investigated. For this purpose, a Pearson correlation coefficient was used to measure the relationship between each of the individual parameters. This indicator calculates the correlation between two variables and returns a value from -1 to 1 , where -1 represents a total negative correlation and 1 a total positive correlation; whereas 0 denotes no correlation (Benesty, et al., 2009). First, energy consumption and comfort levels have been tested showing very weak, almost neutral, correlation with the higher result of -0.2 obtained between energy consumption and thermal comfort. This was an expected outcome given that heating and air conditioning weren't taken into account according to the initial assumptions.

Similarly, no strong correlation between energy consumption and environmental factors has been found. The highest result between energy consumption and humidity equal to 0.4 is too weak to build any binding conclusions on it.

Also, surprisingly, no correlation between comfort levels and environmental factors has been found. Although it was expected to reveal stronger correlation between temperature and thermal comfort, or noise and acoustic comfort which intuitively seem to be an obvious association. The data however reveal no such relation. The highest result of 0.3 was between thermal comfort and noise. This may indicate that the thermal tolerance and the sensibility for other environmental factors of the sample group was too diverse to be able to form a binding conclusions.

\section{Discussion And Conclusions}

\subsection{Main findings and their implications}

The analysis of user behavior uncovered regular occupation pattern during the week. Comparison of this pattern with energy consumption revealed a positive correlation between occupation and energy consumption. In spite of that, it was observed that more than a half of energy was consumed afterhours 
when no users' activity was registered. This consumption was rendered by servers and some workstations that were turned on $24 / 7$.

In order to obtain a more in depth insight, several indicators were used to compare the energy efficiency in different periods. This revealed that while measuring energy efficiency in terms of kWh per surface area is a useful metric for comparing building physical properties, it encourages less efficient use of space since no user activity is taken into account. Thus, indicators that includes coefficient of person hours are more reliable for measuring performance and ideally combination of both - space and person hours give a more objective overview on operation efficiency.

Analysis of energy usage during the lock down period revealed substantial use of energy, meanwhile very low or minimal energy usage was expected. It was because some employees used their home computers only as terminals, while the actual tasks were performed on the lab computers with remote desktop connection. These computers were turned on 24/7, which explains higher energy consumption. Also, a very important aspect to stress regarding home office is that energy consumed by each employee at their home was not included, however it is very important to take this into account as it forms a part of the overall amount of energy consumed. Including this consumption to the amount of energy consumed in the office may reveal that such combined mode of working is less energy efficient than fully in-person or fully homeworking mode. However, more research is required to verify this hypothesis.

The comfort level based on users' opinion revealed general satisfaction with relatively small amount of extreme opinions. However, further investigation exposed that users' opinion did not correlate with objective values from sensors and those defined in the standards, especially regarding temperature. Users acknowledged feeling comfortable while the temperature values were out of the scope defined in the standard. Further experiment showed that users do not rely on the comfort feedback mechanism, probably because they cannot see a direct impact between expressing their opinion and immediate adjustment of the ambient conditions. They prefer to act and adjust the environmental parameters by themselves (turning off the heating, opening windows, etc.) instead of voting. What is more, it was proved that optimal comfort conditions for everyone does not exist. Comfort standards are general, but the actual comfort or discomfort sensation is very personal and related with such aspects as users' gender or provenience. This is a very important factor to keep in mind since building managers usually adjust ambience conditions according to the standards. This study shows that objective conditions defined in standards may diverge from those percepts by the users. For this reason, a more user-centered approach in building operations should be sought.

To find out possible correlation between energy consumption, comfort, and indoor ambient factors, a Pearson coefficient was calculated. This exercise however, exposed very weak, close to neutral, correlations which is not enough to be able to state binding conclusions.

\subsection{Practical recommendations}


Based on the results of this study it is possible to define a set of actions aiming to reduce energy consumption. First of all, the space was occupied unevenly leading to high concentrations of users during short periods of time and leaving the space unoccupied during most of the time. Changing the users' distribution or adjusting the working hours to increase the time of space occupancy would lead to a more efficient use of space as well as energy.

Servers contributed considerably to the overall consumption. Since they are important part of the tasks performed in the lab, they cannot be turned off. Nevertheless, there are still some possibilities to reduce their impact. The servers may be replaced by newer and more efficient devices. Migration to one physical machine with few virtual servers should also be considered. It was calculated that reducing the number of servers to one by creating virtual machines would decrease the energy consumption by $14.5 \%$ in the summer and by $12.3 \%$ in the winter period, which is a considerable amount.

It was also observed that some workstations were turned on constantly, being the cause of the majority

of energy consumed. It should be further analyzed whether there is a need to keep these computers on all the time or maybe they can be turned off at least for some periods. An ideal hypothetical scenario in which all workstations are turned off when unused, would allow for reduction of energy consumption by $26 \%$ in the summer period and by $36.5 \%$ in the winter period. This shows that possibilities for energy optimization are wide. Combination of operational efficiency (optimization of servers) together with behavioral changes of users (turning off the workstations when unused) offer great opportunities for optimization in the range of $40.5 \%$ in the summer and $48,8 \%$ in the winter period, which is in line with $30 \%-50 \%$ shown by Laslaet al. (2019) and $42 \%$ energy savings demonstrated by Ericson et al. (2014).

This is strongly related with energy education and energy awareness which should go on in parallel with operational energy efficiency. Users should be informed on the amount of energy they consume and its impact in terms of economic and environmental footprint. An eco-feedback mechanism may be used for that purpose. It is effective tool that provides building occupants with information regarding their energy consumption, usually in a user-friendly way. Scientific energy units are not easy to comprehend for everyone, however the information may be presented in a more intuitive form, for example, number of trees needed to balance the produced carbon footprint. Such presentation of energy impact may be a good alternative to the formal units since users need to understand the potential consequences of their overconsumption. The same mechanism may also advice users on activities and possible changes in their behavior to increase the energy efficiency. In addition, comparison of consumption to that of peers is also an efficient tool.

\section{Declarations}

\section{Funding}

This work was supported by CROWDSAVING project (Ref: TIN2016-79726-C2-2-R) funded by the Spanish Ministry of Economic Affairs and Digital Transformation, as well as the European Union's Horizon 2020 ELand project (grant agreement 824388). 


\section{Ethics approval and consent to participate}

Not applicable.

\section{Consent for publication}

Not applicable.

\section{Competing interests}

The authors declare that they have no competing interests.

\section{Availability of data and materials}

The datasets used and analyzed during the current study are available from the corresponding author on reasonable request.

\section{Authors' contributions}

JMF: concept of the study; RR: design and coordination. All coauthors (RR, JMF and JCL) were equally involved in the process of data acquisition, analysis, interpretation and drawing conclusions.

\section{References}

1. Aragon, V., Gauthier, S., Warren, P., James, P. A., \& Anderson, B. (2019). Developing English domestic occupancy profiles. Building Research \& Information, 47(4), 375-393.

2. ASHRAE (American Society of Heating and Refrigerating Engineers). (1997), Handbook of Fundamentals: Physiological Principles, Comfort, Health, New York.

3. ASHRAEE (AMERICAN SOCIETY OF HEATING, REFRIGERATING \& AIR-CONDITIONING ENGINEERS). (2017). Standard 55: thermal environmental conditions for human occupancy.

4. Benesty, J., Chen, J., Huang, Y., \& Cohen, I. (2009). Pearson correlation coefficient. In Noise reduction in speech processing(pp. 1-4). Springer, Berlin, Heidelberg.

5. Calì, D., Osterhage, T., Streblow, R., \& Müller, D. (2016). Energy performance gap in refurbished German dwellings: Lesson learned from a field test. Energy and buildings, 127, 1146-1158.

6. CEN, EN (2007). 15251, Indoor environmental input parameters for design and assessment of energy performance of buildings addressing indoor air quality, thermal environment, lighting and acoustics. European Committee for Standardization, Brussels, Belgium.

7. D'Oca, S., \& Hong, T. (2015). Occupancy schedules learning process through a data mining framework. Energy and Buildings, 88, 395-408.

8. Djekic, J., Djukic, A., Vukmirovic, M., Djekic, P., \& Brankovic, M. D. (2018). Thermal comfort of pedestrian spaces and the influence of pavement materials on warming up during summer. Energy and buildings, 159, 474-485. 
9. Dooley, K. (2011, October). New ways of working: Linking energy consumption to people. In Proceedings at the World Sustainable Building Conference SB.

10. Duarte, C., Van Den Wymelenberg, K., \& Rieger, C. (2013). Revealing occupancy patterns in an office building through the use of occupancy sensor data. Energy and buildings, 67, 587-595.

11. Erickson, V. L., Carreira-Perpiñán, M. Á., \& Cerpa, A. E. (2014). Occupancy modeling and prediction for building energy management. ACM Transactions on Sensor Networks (TOSN), 10(3), 1-28.

12. EU Directive 2003/10/EC. (2003) of The European Parliament and of the Council of 6 February 2003 on the minimum health and safety requirements regarding the exposure of workers to the risks arising from physical agents (noise)(Seventeenth individual Directive within the meaning of Article 16(1) of Directive 89/391/EEC

13. Fanger, P. O. (1970). Thermal comfort. Analysis and applications in environmental engineering. Thermal comfort. Analysis and applications in environmental engineering.

14. Gagge, A. P., Stolwijk, J. A. J., \& Hardy, J. D. (1967). Comfort and thermal sensations and associated physiological responses at various ambient temperatures. Environmental research, 1(1), 1-20.

15. Haynes, B. P. (2007). Office productivity: a shift from cost reduction to human contribution. Facilities, $25,452-462$.

16. Haynes, B., Suckley, L., \& Nunnington, N. (2017). Workplace productivity and office type: an evaluation of office occupier differences based on age and gender. Journal of Corporate Real Estate, $19,111-138$

17. Horr, Y., Arif, M., Kaushik, A., Mazroei, A., Katafygiotou, M., \& Elsarrag, E. (2016). Occupant productivity and office indoor environment quality: A review of the literature. Building and environment, 105, 369-389.

18. Huovila, A., Tuominen, P., \& Airaksinen, M. (2017). Effects of building occupancy on indicators of energy efficiency. Energies, 10(5), 628.

19. ISO Standard 7730, (2005). Ergonomics of the thermal environment-Analytical determination and interpretation of thermal comfort using calculation of the PMV and PPD indices and local thermal comfort criteria. BSEN ISO, 7730, 2005.

20. Karatas, A., Stoiko, A., \& Menassa, C. C. (2016). Framework for selecting occupancy-focused energy interventions in buildings. Building Research \& Information, 44(5-6), 535-551.

21. Lasla, N., Doudou, M., Djenouri, D., Ouadjaout, A., \& Zizoua, C. (2019). Wireless energy efficient occupancy-monitoring system for smart buildings. Pervasive and Mobile Computing, 59, 101037.

22. Li, K., Hu, C., Liu, G., \& Xue, W. (2015). Building's electricity consumption prediction using optimized artificial neural networks and principal component analysis. Energy and Buildings, 108, 106-113.

23. Martani, C., Lee, D., Robinson, P., Britter, R., \& Ratti, C. (2012). ENERNET: Studying the dynamic relationship between building occupancy and energy consumption. Energy and Buildings, 47, 584591. 
24. Martell, M., Rodríguez, F., Castilla, M., \& Berenguel, M. (2020). Multiobjective control architecture to estimate optimal set points for user comfort and energy saving in buildings. ISA transactions, 99, 454-464.

25. Martincigh, L., Bianchi, F., Di Guida, M., \& Perrucci, G. (2016). The occupants' perspective as catalyst for less energy intensive buildings. Energy and Buildings, 115, 94-101.

26. cat. (2020). Estacions Meteorològiques. Retrieved 14 December 2020, from https://www.meteo.cat/wpweb/climatologia/serveis-i-dades-climatiques/anuaris-de-dadesmeteorologiques/xarxa-destacions-meteorologiques-automatiques/

27. Mikulik, J. (2018). Energy Demand Patterns in an Office Building: A Case Study in Kraków (Southern Poland). Sustainability, 10(8), 2901.

28. Ministerio de Fomento. (2019). Documento Básico. Seguridad en caso de incendio. Secretaría de Estado de Infraestructuras, Transporte y Vivienda, Spain.

29. Paone, A., \& Bacher, J. P. (2018). The impact of building occupant behavior on energy efficiency and methods to influence it: A review of the state of the art. Energies, 11(4), 953.

30. Pérez-Lombard, L., Ortiz, J., \& Pout, C. (2008). A review on buildings energy consumption information. Energy and buildings, 40(3), 394-398.

31. Sandels, C., Widén, J., Nordström, L., \& Andersson, E. (2015). Day-ahead predictions of electricity consumption in a Swedish office building from weather, occupancy, and temporal data. Energy and Buildings, 108, 279-290.

32. Santin, O. G. (2011). Behavioural patterns and user profiles related to energy consumption for heating. Energy and Buildings, 43(10), 2662-2672.

33. Song, K., Kwon, N., Anderson, K., Park, M., Lee, H. S., \& Lee, S. (2017). Predicting hourly energy consumption in buildings using occupancy-related characteristics of end-user groups. Energy and Buildings, 156, 121-133.

34. Taylor, C. E. (2015). Occupancy matching. Energy Engineering, 112(3), 11-21.

35. UNI EN. 12464-1: 2011. Light and lighting. Lighting of work places. Part, 1.

36. Virote, J., \& Neves-Silva, R. (2012). Stochastic models for building energy prediction based on occupant behavior assessment. Energy and Buildings, 53, 183-193.

37. Wang, Z., \& Ding, Y. (2015). An occupant-based energy consumption prediction model for office equipment. Energy and Buildings, 109, 12-22.

38. Yan, D., O'Brien, W., Hong, T., Feng, X., Gunay, H. B., Tahmasebi, F., \& Mahdavi, A. (2015). Occupant behavior modeling for building performance simulation: Current state and future challenges. Energy and Buildings, 107, 264-278.

39. Yang, J., Santamouris, M., \& Lee, S. E. (2016). Review of occupancy sensing systems and occupancy modeling methodologies for the application in institutional buildings. Energy and Buildings, 121, 344-349. 
40. Yang, L., Yan, H., \& Lam, J. C. (2014). Thermal comfort and building energy consumption implications-a review. Applied energy, 115, 164-173.

41. Yezioro, A., Dong, B., \& Leite, F. (2008). An applied artificial intelligence approach towards assessing building performance simulation tools. Energy and Buildings, 40(4), 612-620.

42. Zhao, H. X., \& Magoulès, F. (2012). A review on the prediction of building energy consumption. Renewable and Sustainable Energy Reviews, 16(6), 3586-3592.

43. Zhao, D., McCoy, A. P., Du, J., Agee, P., \& Lu, Y. (2017). Interaction effects of building technology and resident behavior on energy consumption in residential buildings. Energy and Buildings, 134, 223233.

44. Zhu, T., Xiao, S., Zhang, Q., Gu, Y., Yi, P., \& Li, Y. (2015). Emergent technologies in big data sensing: a survey. International Journal of Distributed Sensor Networks, 11(10), 902982.

\section{Figures}

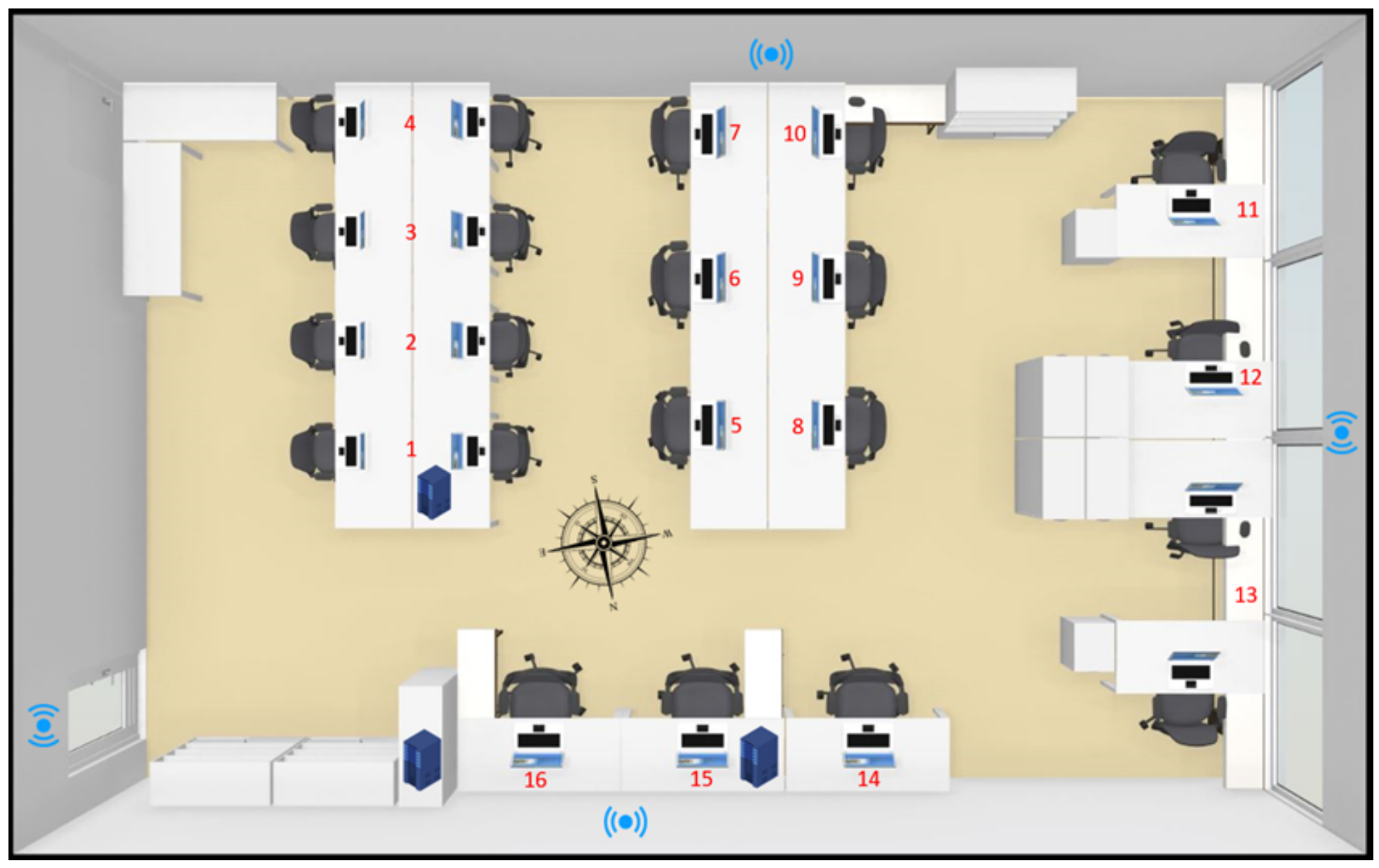

Figure 1

A lookout of the $72 \mathrm{~m} 2$ office lab were the experimentation took place. The workstations were numbered 1 - 16 according to energy supply sockets (workstation 13 is shared) and location of four sensor kits has been marked with blue icons. 


\section{$\equiv \quad$ Crowd Saving}

GENERAL COMFORT
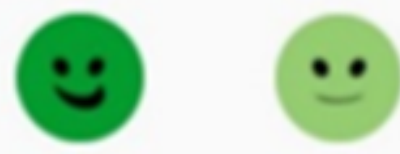

\section{$\bullet$}

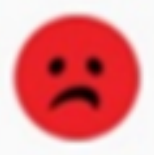

THERMAL COMFORT
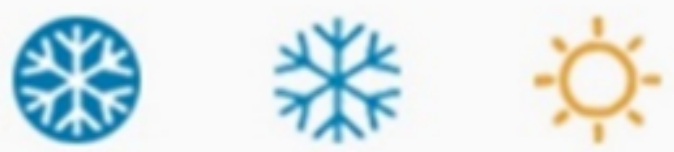

LIGHTING
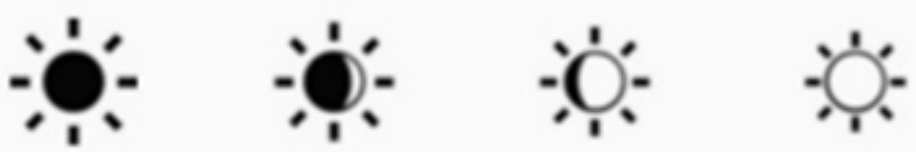

NOISE (happy or not)
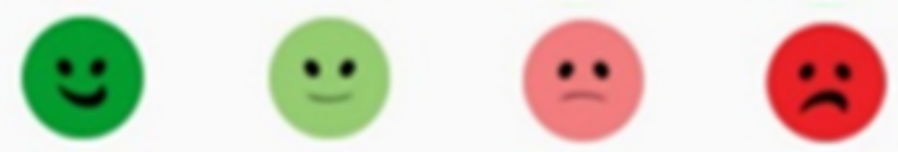

LOCATION:

1

1

\section{SEND}

\section{Figure 2}

User interface of the app for crowd sensing the occupants behavior and feedback on level of comfort sensation. 


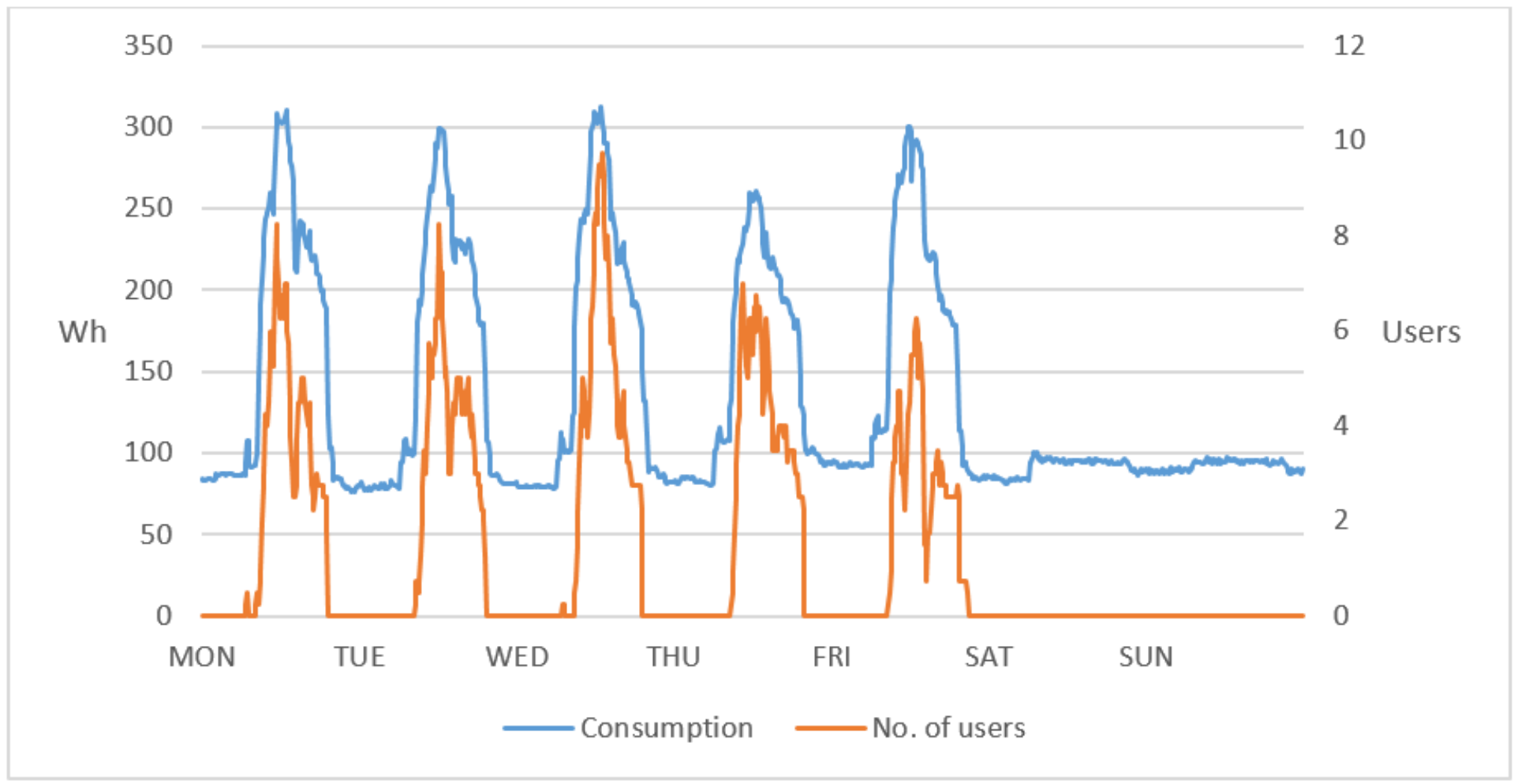

\section{Figure 3}

relation between occupation pattern (user behavior) and energy consumption -obtained from avaraged values encompassing a period of four weeks.

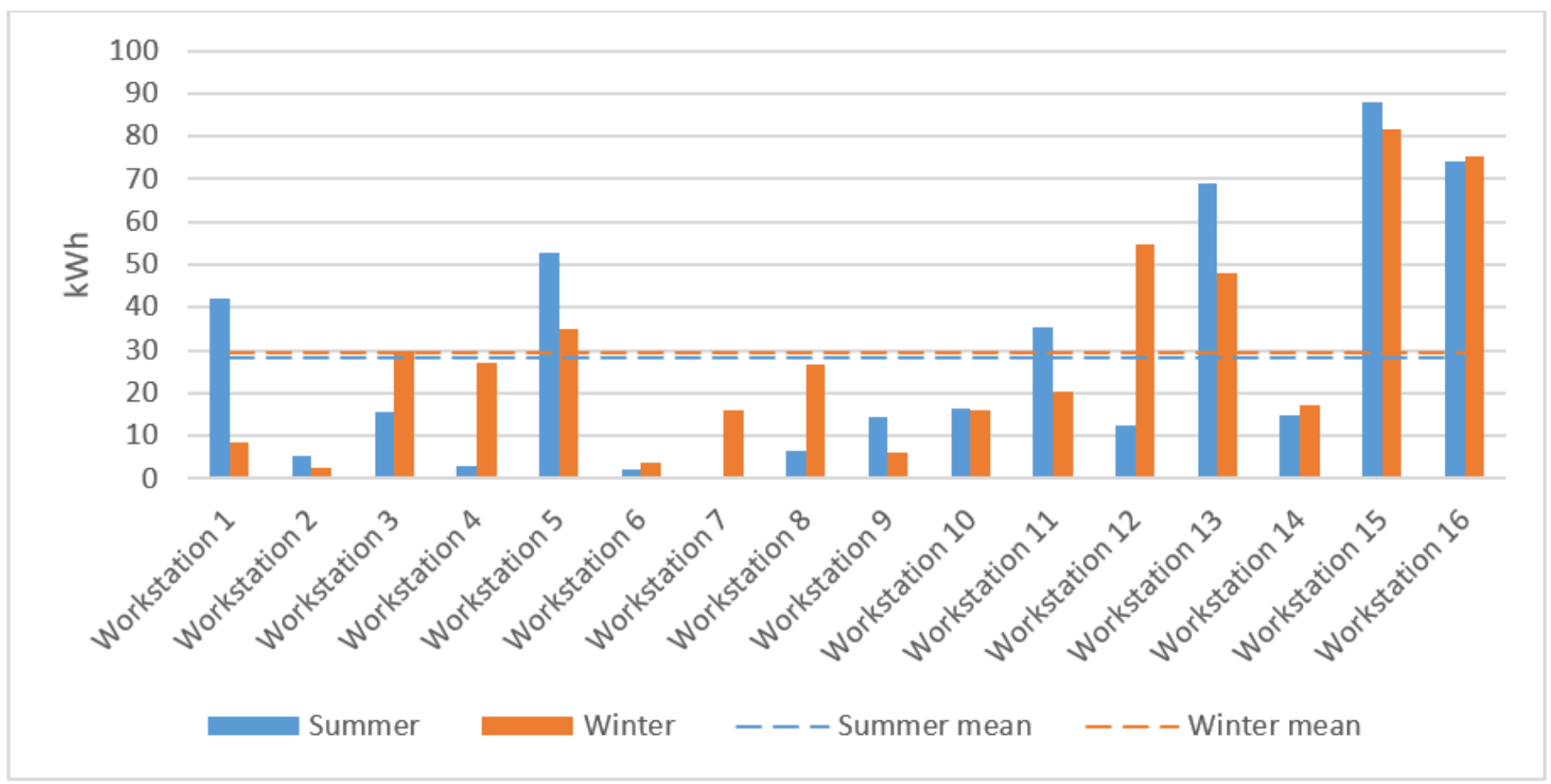

Figure 4 
Comparison of energy consumption per workstation in the summer and the winter period.

\section{General comfort}

$100 \%$

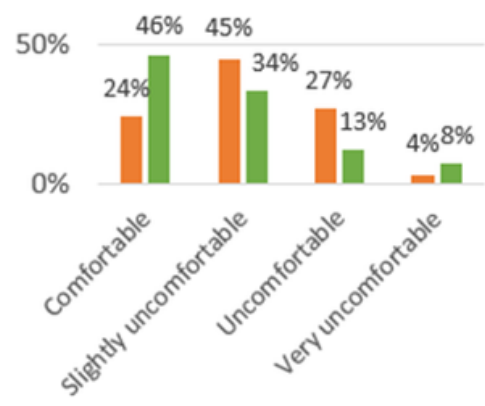

Thermal comfort

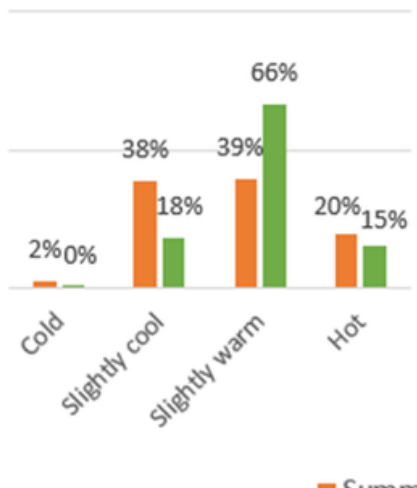

Visual comfort
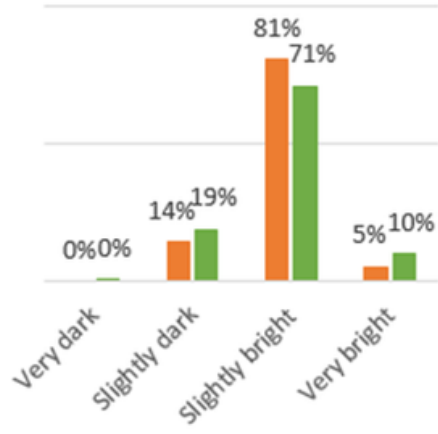

Acoustic comfort

ㅁummer - Winter

\section{Figure 5}

Comparison of comfort levels based on users' feedback for the summer and winter periods.

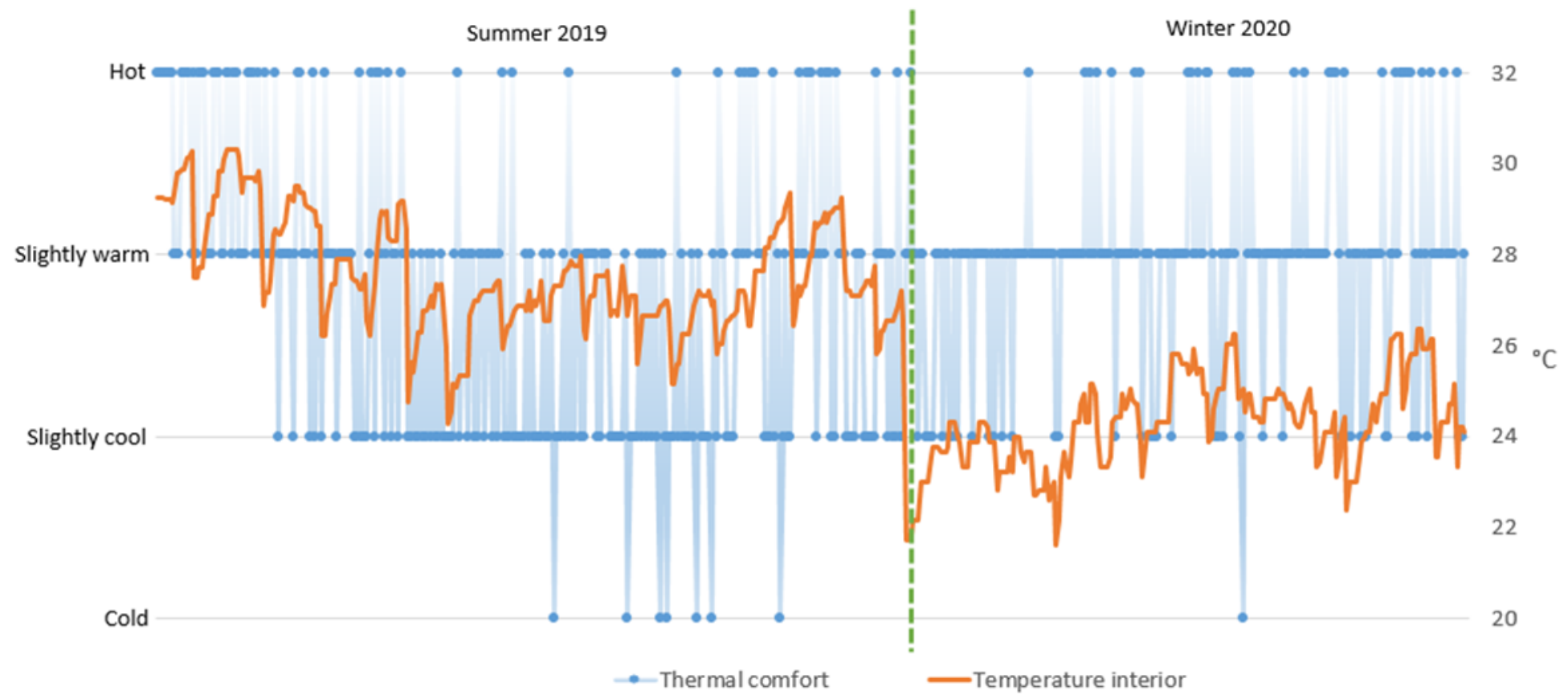

\section{Figure 6}

Comparison of interior temperature with thermal comfort in the summer and winter periods. 


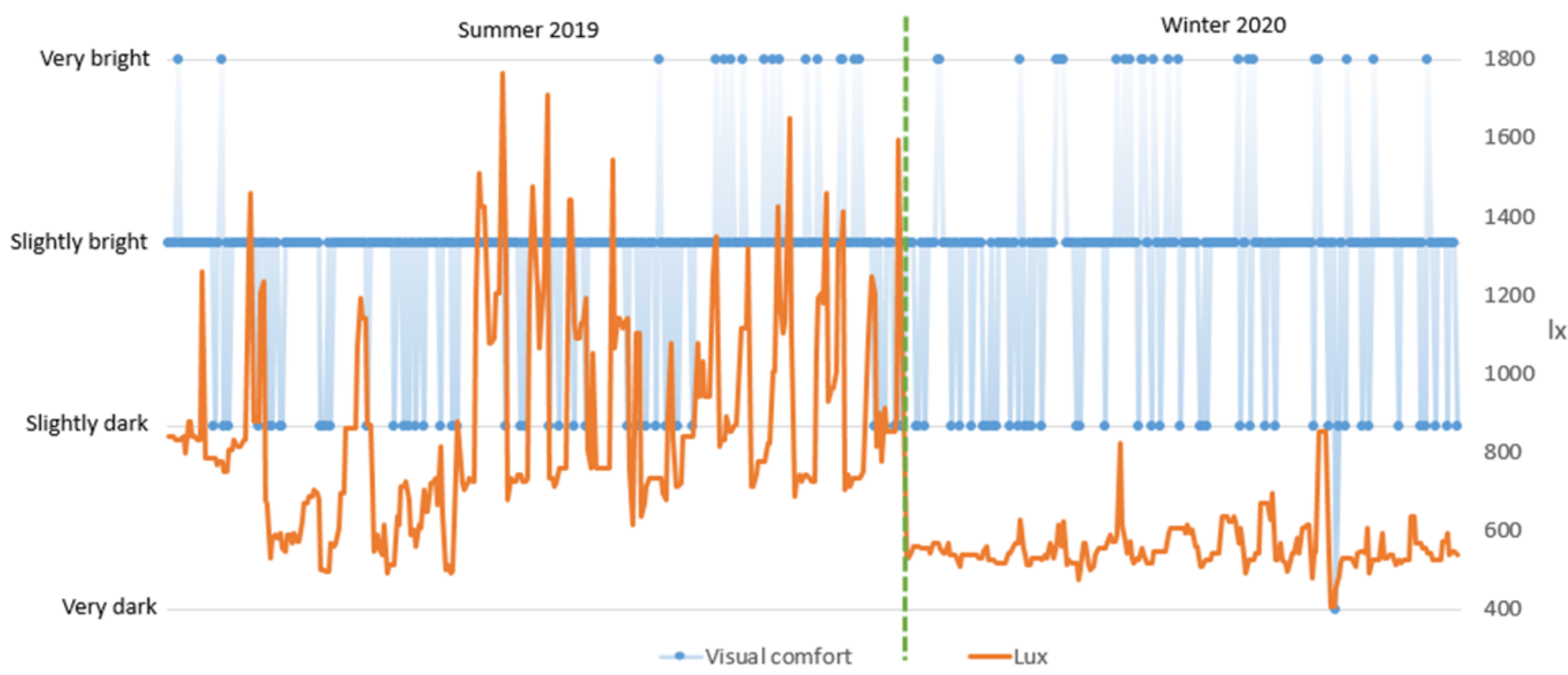

\section{Figure 7}

Comparison of light levels with visual comfort in the summer and winter periods.

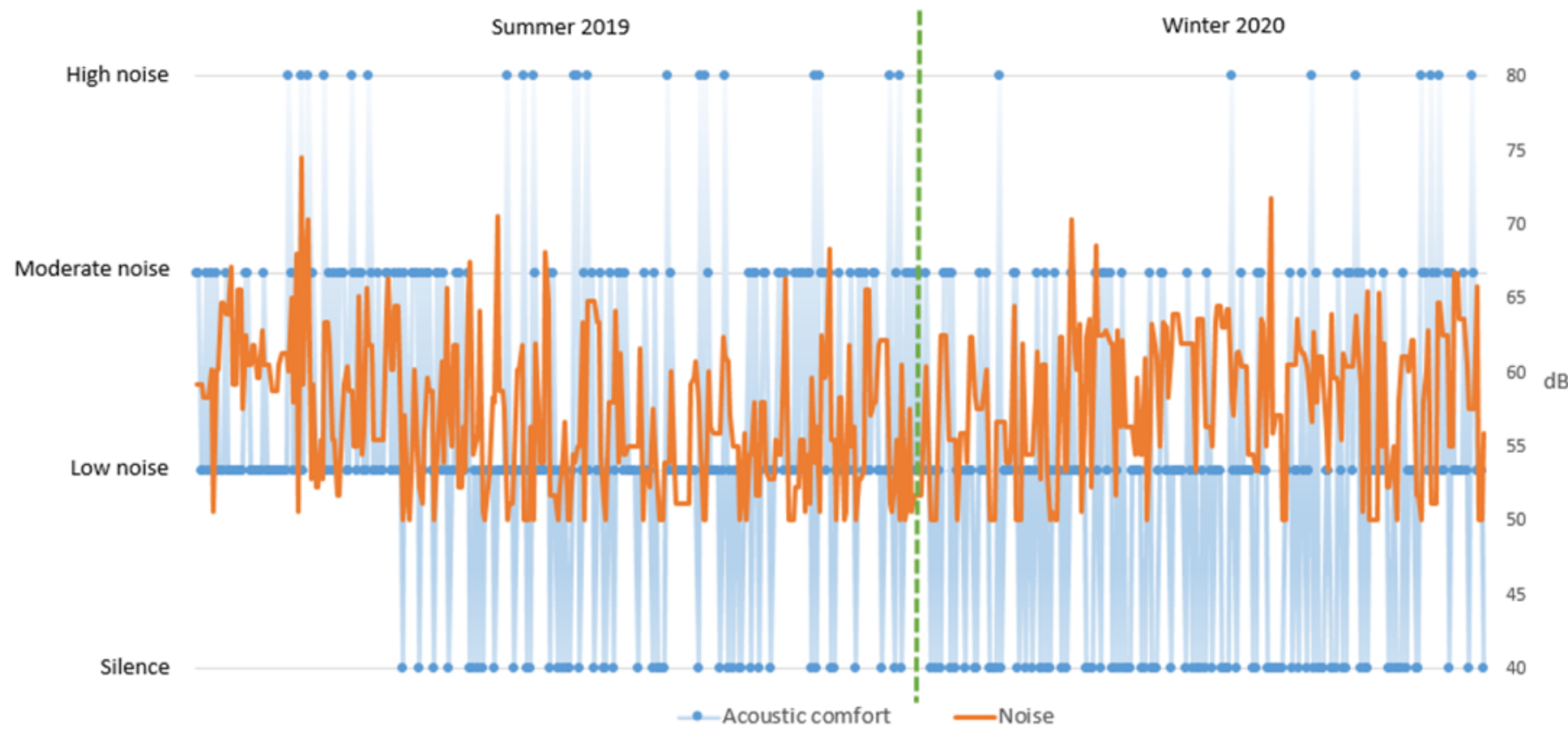

\section{Figure 8}

Comparison of noise levels with Acoustic comfort in the summer and winter periods. 


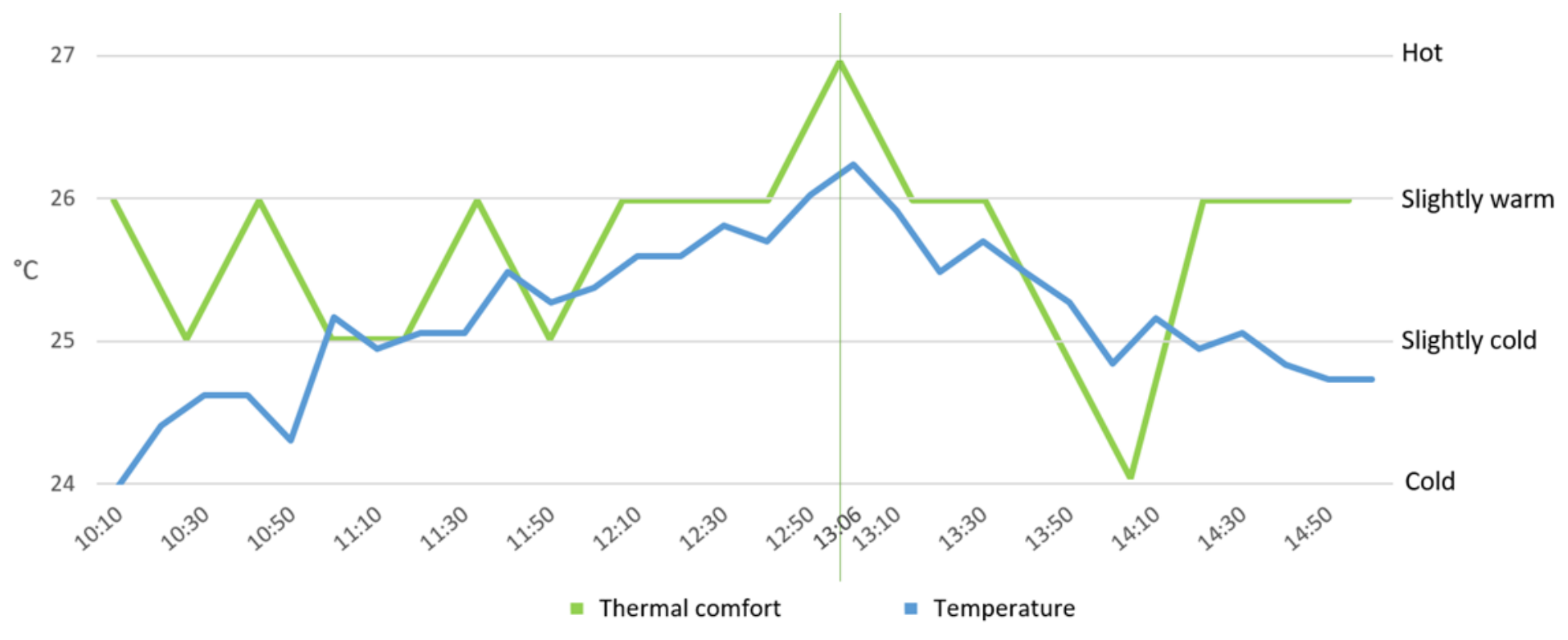

Figure 9

Curve of thermal comfort threshold together with users' comfort sensation. 